\title{
Family Support as Predictor of Adhernce to Diet Regimen among People with Type II Diabetes in Lagos State
}

\author{
Haastrup, E.A, Daki, L.O and Tijani, A.J \\ Department of Human Kinetics and Health Education University of Lagos, Akoka-Nigeria
}

\begin{abstract}
The purpose of this study was to find out if support of family members will help people with diabetes (in Lagos Metropolis) to adhere to diet regimen in managing diabetes. Three research questions were raised and three hypotheses were tested on presence of family, diabetes knowledge of family and family involvement. A total of 120 people with diabetes were surveyed using a self-developed structured and validated questionnaire from the three tiers of health facilities in Lagos metropolis. The reliability of the instrument was determined as 0.81 using a Test Re-test method of reliability. The findings of this study are that living with a family member, family members' knowledge and family involvement will affect people with diabetes adherence to diet regimen. The study recommended that scaling up diabetes programmes, encouraging families of people with diabetes to attend clinics and establishing a functional diabetes group should be advocated.
\end{abstract}

\section{Introduction}

Non-communicable diseases now constitute the leading cause of global disease burden in most countries of the world. The most devastating of these groups of diseases is diabetes mellitus. Apart from its rapid increase in prevalence, diabetes mellitus has the ability to predispose people to the non-communicable diseases. Complications arising from diabetes according to the International Diabetes Federation (2003) include; coronary artery and peripheral vascular disease,stroke, diabetic neuropathy, amputations, renal failure and blindness. The same body estimated that approximately, 246 million people in the age range 20-79 had diabetes in 2007. It is estimated that by 2025 , this figure will increase to 380 million or $7.1 \%$ of the adult population. Focusing on Nigeria, the International Diabetes Federation (2009) projected an estimated prevalence of $5.5 \%$ by 2030. This should be a matter of concern as our poor attitude to preventive measures and inadequate medical facilities.

\section{Frame Work}

That diabetes is preventable and manageable is a position that is established by various researchers. Fowler (2010) documented that lifestyle therapies are the cornerstone of diabetes treatment. An unhealthy lifestyle featuring a lack of physical activity and excessive eating initiates and propagates the majority of diabetes and its eventual complications. As also noted by Fowler (2010), research evidence supports the inclusion of dietary and lifestyle modification as a mainstay of therapy to control diabetes. Harri, Petrella, Lambert-Lanning, Leadbetter, and Cranston (2004) documented that numerous studies have demonstrated that physical activity and dietary interventions improve glycaemic control in patients diagnosed with type 2 diabetes, and that these interventions can also delay and possibly prevent onset of the disease in patients with identified Impaired Glucose Tolerance (IGT) who are at risk of developing diabetes later in life. Benhalima and Mathieu (2009) noted that in all patients with type 2 diabetes, lifestyle advice on nutritional habits and exercise should be part of the therapy. The main focus should be on healthy, balanced diets, aimed at maintaining normal weight and avoiding overweight. Also that these lifestyle interventions should be maintained throughout the life of type 2 diabetic patients, as they not only positively affect glucose levels, but also have beneficial effects on other cardiovascular risk factors, such as blood pressure and lipids.

The Scottish Intercollegiate Guidelines Network (2010) also stated that modification of adverse lifestyle factors is an important aspect of the management of all types of diabetes. In particular, appropriate management of cardiovascular risk factors such as smoking, physical inactivity and poor diet is important for the prevention of macrovascular disease. The Network further stated that helping patients to modify certain lifestyle and dietary behaviours should take account factors such as the patient's willingness to change, their perception of their diabetes, support system, and factors which may be indirectly related to their diabetes, such as depression and adverse effects on quality of life.

\section{Family Involvement}

The involvement of the family in diabetes management has also been stressed by research. The Scottish Intercollegiate Guidelines Network (2010) recommended that healthcare professionals should involve carers and family members in diabetes education and care. Also healthcare professionals should encourage family support 
and understanding on all the lifestyle and dietary therapy needed for successful management of the disease condition.

It further recommended that people living with diabetes should speak to their family members about their diabetes including the dietary therapy needed in the management of diabetes. It argued that this measure will not only play an important role in the adequate management of diabetes, but will also encourage diabetes awareness in the family members which can help to prevent the development of type 2 diabetes in their first degree relatives through early and appropriate lifestyle modification. Macaulay, Paradis, Potvin, Cross, SaadHaddad, McComber, Desrosiers, Kirby, Montour, Lamping, Leduc and Rivard (1997) also argued that effective diabetes management programs in young people should be skill based rather than knowledge based only, and should include the family and community support, with provision of healthy foods and opportunities for physical activity.

This position is also supported by Diabetes Care and Education Committee of the Banting and Best Diabetes Centre of the University of Toronto (2009). According to this source, the overall goals of medical nutrition therapy (MNT) in the management of diabetes are to improve or maintain quality of life, nutritional status and physiological health, and to reduce the risk or treat the acute and long-term complications of diabetes and the associated co-morbidities. In order to achieve this, the Centre recommended that medical nutrition therapy in the management of diabetes should involve the family members or significant others who are involved in supporting the individual.

\section{Objectives Of The Study}

The main objective of the study is to find out if support of family members will help diabetic patients to adhere to diet regimen in managing diabetes. Other objectives of the study focus on establishing the extent to which the following variables will promote adherence to diet regimen in the management of diabetes.

- $\quad$ Family members' knowledge of diet management of diabetics.

- $\quad$ Eating together by family member, and

Appropriate eating schedule by the diabetic.

\section{Research Hypotheses}

The following research hypotheses were tested by this study:

1. Living with a family member will not significantly affect adherence to diet regimen among people with the type II diabetes in Lagos metropolis.

2. Family member's knowledge of diabetes will not significantly affect adherence to diet regimen among people with the type II diabetes in Lagos metropolis.

3. Family involvement will not significantly affect adherence to diet regimen among people with the type II diabetes in Lagos metropolis.

\section{Research Method}

\section{Methods And Procedure}

Descriptive survey method was used for the study. The method is considered most appropriate because of its merit in providing wide scope for obtaining information. The plan of the study involved the use of questionnaire to collect data in order to test stated hypotheses raised in the study.

\section{Population}

The population for this study comprised everyone with type II diabetes in Lagos metropolis attending health facilities in the three tiers of health care in Lagos metropolis.

\section{Sample and Sampling Techniques}

A total of 120 people with diabetes type II were surveyed from three tiers of health facilities (teaching hospital, general hospital and health centres) in Lagos Metropolis. Sample was drawn from among outpatient clients attending the following health facilities: Lagos University Teaching Hospital (LUTH), Lagos State University Teaching Hospital (LASUTH), Onikan General Hospital and Oshodi Primary Health care. Since the teaching hospital has designated clinics for people with diabetes, a large number of the sample were drawn from LUTH.

\section{Research Instrument}

A self-structured questionnaire was used for data collection. The questionnaire consists of two sections; sections A and B. Section A focused on demographic data of respondents. Variables in this section include, age, sex, marital status, religion, educational background, employment status and the number of people living with respondent. Section B featured statements to establish the level of family involvement, meal planning, family 
knowledge and presence of family members in the dietary regimen of people with diabetes. The face and content validity was used to determine the validity of the study. The Test Re-test method of reliability was used to ascertain the reliability of the instrument. Pearson Product Moment Correlation was used to determine the reliability of the instrument as 0.81 .

\section{Method of Data Collection}

Ethical letter-: Letter of permission to carry out the research was written to the Research and Ethics Committee of LUTH, LASUTH and Lagos State Heath Commission stating the purpose and significance of the study. Based on this request, approval was granted. Subsequently, data were collected from LUTH, LASUTH, Onikan General Hospital and Oshodi HPC.

Two research assistants were recruited and trained for the purpose of data collection. Copies of the questionnaire were administered to respondents by the researcher and the two research assistants during the various clinic days for people with diabetes in the selected health facilities.

\section{Data Analysis}

Data analysis was done using the descriptive statistics of frequency count and percentages, specifically used to present the demographic data while the inferential statistics of Chi-square was used to test all stated hypotheses at 0.05 Alpha level.

\section{Result And Discussion}

Table 1: Distribution of respondents by Health facility

\begin{tabular}{lll|}
\hline Study Centers & Frequency & Percentage \\
LUTH & 55 & 45.9 \\
LASUTH & 40 & 33.3 \\
Onikan Health Center & 10 & 8.3 \\
Oshodi Health Center & 15 & 12.5 \\
Total & $\mathbf{1 2 0}$ & $\mathbf{1 0 0}$ \\
\hline
\end{tabular}

Table 1 above represents the numbers and percentage of respondents sampled from health Institutions that represent the three tiers of government. LUTH (Federal); LASUTH (State); Onikan Health Center and Oshodi Health Center (primary health centers)

Table 2: Sex and mean age of respondents

\begin{tabular}{llll|} 
Sex & Frequency & Percentage & Mean Age \\
Female & 62 & 53 & 57 \\
Male & 55 & 47 & 62 \\
Total & $\mathbf{1 1 7}$ & $\mathbf{1 0 0}$ & $\mathbf{1 1 9}$ \\
\hline
\end{tabular}

From the table 2 above, 62(53\%) of the respondents were females while 55(47\%) were males. The mean age of female respondents was calculated to be 57 years while that of male respondents was 62 years.

Table 3: Demographic distribution of respondents

\begin{tabular}{|c|c|c|}
\hline Characteristics & Response & Frequency \\
\hline \multirow{4}{*}{ Marital Status } & Single & $8(6.7 \%)$ \\
\hline & Married & $76(63.3 \%)$ \\
\hline & Divorced & $36(30 \%)$ \\
\hline & Total & 120 \\
\hline \multirow{4}{*}{ Religion } & Christianity & $65(54.2 \%)$ \\
\hline & Islam & $55(45.8 \%)$ \\
\hline & Indigenous & - \\
\hline & Total & 120 \\
\hline \multirow{5}{*}{ Educational Background } & No Formal Education & $37(30.8 \%)$ \\
\hline & Primary & $18(15 \%)$ \\
\hline & Secondary & $19(15.8 \%)$ \\
\hline & Tertiary & $46(38.3 \%)$ \\
\hline & Total & 120 \\
\hline \multirow{5}{*}{ Employment Status } & Full-time & $45(37.5 \%)$ \\
\hline & Part-time & $11(9.2 \%)$ \\
\hline & Unemployed & $22(18.3 \%)$ \\
\hline & Retired & $42(35 \%)$ \\
\hline & Total & 120 \\
\hline \multirow{4}{*}{ People living } & Alone & $16(13.3 \%)$ \\
\hline & One & $9(8.3 \%)$ \\
\hline & Two & $44(36.7 \%)$ \\
\hline & Three & $23(19.2 \%)$ \\
\hline
\end{tabular}


From table 3 above, $8(6.7 \%)$ were singles, 76(63.3\%) were married while $36(30 \%)$ were divorced. Majority of the respondents $65(54.2 \%)$ practiced Christianity while 55(45.8\%) practiced Islam. 37(30.8\%) of the respondents had no formal education, 18(15\%) had only primary education, 19 (15.8\%) had secondary education while $46(38.3 \%)$ had tertiary education. $45(37.5 \%)$ of the respondents were full-time workers, $11(9.2 \%)$ were part-time workers, $22(18.3 \%)$ were unemployed while $42(35 \%)$ of the respondents were retired. In terms of the number of people living with the respondents, $16(13.3 \%)$ of the respondents stay alone, $9(8.3 \%)$ had one person living with them, 44(36.7\%) had two persons living with them, 23(19.2\%) had three family members living with them while $27(22.5 \%)$ had four and more family members living with them.

Table 4: Distribution of respondents by diabetes status

\begin{tabular}{|cll|}
\hline Characteristics & Response & Frequency \\
Are you on recommended & Yes & $95(79.2 \%)$ \\
diet & No & $25(20.8 \%)$ \\
& Total & $\mathbf{1 2 0}$ \\
Do you belong to a diabetes & Yes & $9(7.5 \%)$ \\
support group & No & $111(92.5 \%)$ \\
& Total & $\mathbf{1 2 0}$ \\
\hline
\end{tabular}

From table 4 above, 95(79.2\%) of the respondents were on recommended diet while 25(20.8\%) were not on recommended diet. $9(7.5 \%)$ of the respondents belonged to a diabetes support group while $111(92.5 \%)$ were not in a diabetes support group.

Table 5: Presence of family members

\begin{tabular}{|c|c|c|c|c|c|c|}
\hline $\mathbf{S} / \mathbf{N}$ & Statements & SA & $\mathbf{A}$ & D & SD & Total \\
\hline i. & $\begin{array}{l}\text { Living with people can promote adherence to diabetes food } \\
\text { regimen }\end{array}$ & $37(39 \%)$ & $50(53 \%)$ & $4(4 \%)$ & $4(4 \%)$ & 95 \\
\hline ii. & $\begin{array}{l}\text { Living with family can promote adherence to diabetes food } \\
\text { regimen }\end{array}$ & $23(20 \%)$ & $86(75 \%)$ & $3(3 \%)$ & $3(2 \%)$ & 115 \\
\hline
\end{tabular}

From table 5 above, $87(92 \%)$ and $109(95 \%)$ of the respondents agreed to items i and ii respectively confirming that living with family members enhances adherence to diabetes food regimen. On the other hand $8(8 \%)$ and $6(5 \%)$ of the respondents disagreed to items i and ii respectively.

Table 6: Family Knowledge of Diabetes

\begin{tabular}{|c|c|c|c|c|c|c|}
\hline $\mathbf{S} / \mathbf{N}$ & Statements & $\mathbf{S A}$ & $\mathbf{A}$ & D & SD & Total \\
\hline i. & $\begin{array}{l}\text { Family member's knowledge of diabetes food preparation } \\
\text { enhances adherence to diabetes food regimen }\end{array}$ & $35(30 \%)$ & $79(69 \%)$ & - & $1(0.9 \%)$ & 115 \\
\hline ii. & $\begin{array}{l}\text { Family member's knowledge of selection of appropriate } \\
\text { diabetes diet promote adherence to diabetes food regimen }\end{array}$ & $38(34 \%)$ & $71(64 \%)$ & $1(0.9 \%)$ & $1(0.9 \%)$ & 111 \\
\hline
\end{tabular}

From table 6 above, 114(99\%) and 109(98\%) of the respondents agreed to items i and ii buttressing the fact that knowledge of family members on diabetes will affect adherence to diabetic food regimen. Very few of the respondents $1(0.9 \%)$ and $2(2 \%)$ disagreed with this position.

Table 7: Level of Family involvement

\begin{tabular}{|c|c|c|c|c|c|c|}
\hline $\mathbf{S} / \mathbf{N}$ & Statements & $\begin{array}{l}\text { Almost } \\
\text { Always }\end{array}$ & $\begin{array}{l}\text { Very } \\
\text { Often }\end{array}$ & Sometime & $\begin{array}{l}\text { Not } \\
\text { Often }\end{array}$ & Never \\
\hline i. & $\begin{array}{l}\text { How often does a family member encourage you to eat } \\
\text { the recommended diabetic diet? }\end{array}$ & $26(22 \%)$ & $62(53 \%)$ & $22(18.8 \%)$ & $7(6 \%)$ & - \\
\hline ii. & $\begin{array}{l}\text { How often does a family member tell you not to eat } \\
\text { something you should not eat? }\end{array}$ & $21(18 \%)$ & $38(33 \%)$ & $49(43 \%)$ & $7(6 \%)$ & $1(0.8 \%)$ \\
\hline iii. & $\begin{array}{l}\text { How often does a family member remind you to stick to } \\
\text { your meal plan? }\end{array}$ & $34(28.8 \%)$ & $53(45 \%)$ & $26(22 \%)$ & $5(4 \%)$ & $1(8 \%)$ \\
\hline iv. & $\begin{array}{l}\text { How often does a family member praise you for } \\
\text { following your diet? }\end{array}$ & $25(22.7 \%)$ & $28(25 \%)$ & $38(35 \%)$ & $17(15 \%)$ & $2(\%)$ \\
\hline v. & $\begin{array}{l}\text { How often does a family member disagree with you for } \\
\text { not keeping to your diet? }\end{array}$ & $22(19.3 \%)$ & $50(43 \%)$ & $20(18 \%)$ & $20(18 \%)$ & $2(1.8 \%)$ \\
\hline vi. & $\begin{array}{l}\text { How often does a family member suggest things that } \\
\text { might help you follow your diet? }\end{array}$ & $15(12.8 \%)$ & $52(44 \%)$ & $37(32 \%)$ & $10(9 \%)$ & $3(2.6 \%)$ \\
\hline vii. & $\begin{array}{l}\text { How often does a family member help you to cook foods } \\
\text { that fit your meal plan? }\end{array}$ & $25(21.7 \%)$ & $53(46 \%)$ & $28(24 \%)$ & $6(5 \%)$ & $3(2.6 \%)$ \\
\hline viii. & $\begin{array}{l}\text { How often does a family member talk to you about } \\
\text { taking foods that help you maintain good blood sugar } \\
\text { level? }\end{array}$ & $27(23.7 \%)$ & $45(39 \%)$ & $34(29 \%)$ & $5(4 \%)$ & $3(2.6 \%)$ \\
\hline Ix & $\begin{array}{l}\text { How often do your friends choose to eat healthy food } \\
\text { along with you? }\end{array}$ & $24(21 \%)$ & $45(39 \%)$ & $32(28 \%)$ & $10(9 \%)$ & $3(2.6 \%)$ \\
\hline
\end{tabular}


Family Support as Predictor of Adhernce to Diet Regimen among People with Type II Diabetes .....

Items i-ix in table 7 above solicited information on the level of participation of family members in enhancing adherence to diabetic diet regimen. Positive response to each of the items is above average as indicated in the table: 88(75\%), 59(51\%), 87(28.8\%), 53(47.7\%), 72(62.3\%), 67(56.8\%), 78(67.7\%), 72(62.7\%) and $69(60 \%)$

Testing of Hypotheses and Discussion of Findings

$\mathrm{H}_{1}$ : Living with a family member will not significantly affect diabetes patients' adherence to diet regimen by people living with type II diabetes in Lagos metropolis.

Table 8: Chi-square Analysis of Effect of living with family members

\begin{tabular}{|c|c|c|c|c|c|c|c|}
\hline Variables & $\mathrm{N}$ & df & $\alpha$ significance level & $\begin{array}{l}\text { Calc } X^{2} \\
\text { value }\end{array}$ & $\mathrm{X}^{2} \mathrm{tab}$ & Remark & Decision \\
\hline Living with a family member & 115 & 5 & 0.05 & 118.27 & 9.48 & Significant & Rejected \\
\hline
\end{tabular}

From table 8 above, the calculated $\mathrm{X}^{2}$ value is 118.27 , while the table value is 9.48 at 0.05 alpha level. The calculated $\mathrm{X}^{2}$ value 118.27 is greater than the $\mathrm{X}^{2}$ tabulated of 9.48 . The null hypothesis is thereby rejected. By implication, the alternate hypothesis which states that living with a family member will significantly affect people with diabetes adherence to diet regimen in Lagos metropolis is accepted. This finding is supported by a study conducted by DiMatteo (2004), the association between disease management and social support has been researched extensively in the social and behavioral sciences. The precise mechanism by which social support contributes to health outcomes is not yet completely understood as explained by the author. Research does suggest, however, that social support can benefit patients' health by buffering stress, changing affective states, increasing self-efficacy, and influencing change in negative health behaviors.

Rosland, Kieffer, Israel, Cofield, Palmisano, Sinco, Spencer, Heisler and Gen (2008) found that practical and emotional support received by both family and friends had a positive influence on global measures of disease management in people with diabetes. In fact, a meta-analytic review of 122 empirical studies found that adherence was $27 \%$ higher when patients had practical support available to them. Additionally, research by Pereira et al indicates strong associations between positive family dimensions (eg, cohesion and familial guidance) and better glycemic control among diabetic patients (Pereira, Berg-Cross, Almeida \& Machado, 2008). In regards to family cohesion, in which families are described as warm, accepting, and close, the odds of adherence were three times higher when compared with noncohesive families (DiMatteo, 2004).

$\mathrm{H}_{2}$ : Family member's knowledge of diabetes will not significantly affect diabetes patients' adherence to diet regimen.

Table 9: Chi-square Analysis of family knowledge of diabetes

\begin{tabular}{|llllllll|}
\hline Variables & $\mathrm{N}$ & $\mathrm{df}$ & $\alpha$ significance level & $\begin{array}{l}\text { Calc } \\
\text { value }\end{array}$ & $\mathrm{X}^{2}$ tab & Remark & Decision \\
Family knowledge of Diabetes & 115 & 4 & 0.05 & 176.96 & 7.81 & Significant & Rejected \\
\hline
\end{tabular}

From table 9 above, the calculated $\mathrm{X}^{2}$ value is 176.96, while the table value is 7.81 at 0.05 alpha level. The calculated $\mathrm{X}^{2}$ value 176.96 is greater than the $\mathrm{X}^{2}$ tabulated of 7.81 the null hypothesis is thereby rejected. By implication, the alternate hypothesis which states that family member's knowledge of diabetes will significantly affect people with diabetes adherence to diet regimen in Lagos metropolis. Most theories of health behavior change required for diabetes self- care performance include a social support component (Osborn \& Egede, 2010), and family members are considered a significant source of social support for adults with diabetes (Tang, Brown, Funnell \& Anderson, 2008). Family members can have a positive and/or negative impact on the health of people with diabetes, interfere with or facilitate self-care activities (e.g.,by buying groceries or refilling a prescription), and contribute to or buffer the deleterious effects of stress on glycemic control (Fisher, Chesla \& Skaff, 2000). Family members can provide many kinds of social supports (e.g., emotional, informational, and appraisal support) and instrumental support (i.e., observable actions that make it).

$\mathrm{H}_{3}$ : Family involvement will not significantly affect diabetes patients adherence to diet regimen.

Table 10: Chi-square Analysis of the level of family involvement

\begin{tabular}{|llllllll|}
\hline Variables & $\mathrm{N}$ & $\mathrm{df}$ & $\alpha$ significance level & $\begin{array}{l}\text { Calc } \\
\text { value }\end{array}$ & $\mathrm{X}^{2}$ tab & Remark & Decision \\
Level of family involvement & 118 & 5 & 0.05 & 90.07 & 9.48 & Significant & Rejected \\
\hline
\end{tabular}


From table 10 above, the calculated $\mathrm{X}^{2}$ value is 90.07 , while the table value is 9.48 at 0.05 alpha level. The calculated $X^{2}$ value 90.07 is greater than the $X^{2}$ tabulated of 9.48 the null hypothesis is thereby rejected. By implication, the alternate hypothesis which states that family involvement will not significantly affect people with diabetes adherence to diet regimen in Lagos is accepted. This finding is supported by a study of Osborn and Egede (2010) who reported that most theories of health behavior change required for diabetes self- care performance include a social support component and family members are considered a significant source of social support for adults with diabetes (Tang, Brown, Funnell \& Anderson, 2008).

Family members can have a positive and/or negative impact on the health of people with diabetes, interfere with or facilitate self-care activities (e.g.,by buying groceries or refilling a prescription), and contribute to or buffer the deleterious effects of stress on glycemic control (Fisher, Chesla \& Skaff, 2000). Although family members can provide many kinds of social support (e.g., emotional, informational, and appraisal support), instrumental sup- port (i.e., observable actions that make it). Furthermore, family structural support (ie, patient's marital status and living arrangement) is also positively associated with treatment adherence. In research by DiMatteo, the odds of adherence for married patients were 1.27 times higher than for unmarried patients. Additionally, "living with others" had positive effects on adherence for adults $(r=0.08, P<0.05)$. More specifically, the effect of patient adherence and "living with others" was stronger for behavioral regimens compared with medication regimens. Moreover, in the same study, functional social support (eg, practical and emotional support) had stronger effects on adherence than did structural social support, suggesting that the quality of family-patient relationships matters more than just the mere presence of individuals within a patient's network of support.

The following major findings were revealed in the study:

1. Living with a family member will affect people with diabetes type 2 adherence to diet regimen.

2. Family members' knowledge of diabetes will affect people with diabetes type 2 adherence to diet regimen.

3. Family involvement meal planning will significantly affect people with diabetes' adherence to diet regimen.

\section{Conclusions}

The study concluded that people with diabetes type 2 in Lagos Metropolis have knowledge about diet management of diabetes for the purpose of improving their health. The study also revealed that: appropriate food preparation, family's favourite foods, and family involvement are strong factors in diabetes diet regimen.

\section{Recommendations}

The following recommendations were made by the study:

As a fall out of this study, the following recommendations are suggested:

1. Scaling up diabetes education programme for the general public

2. Encouraging family of people with diabetes to accompany them to clinics and medical appointments

3. Establishment of diabetes group should be encouraged to provide opportunities of networking for people with diabetes.

\section{Further Studies}

Due to time challenge and bureaucratic constraints, the coverage of this study in terms of geographic area and number of respondents was low. It is therefore suggested that a follow-up study should be conducted to compensate for these lapses.

\section{References}

[1]. Akinkugbe O. O. (1997): National expert committee on non-communicable diseases (NCD) in Nigeria Final Report of a National Survey, Lagos; 64-90.

[2]. Albertis K. A, \& Zimmet P. Z (1998). World Health Organization (WHO): Consultation Definition, Diagnosis and Classification of Diabetes Mellitus and Its Complications, Diabetes Medicine 15:539-553.

[3]. Ataru, T. Mitsuo F. Yataka S. et al (2003): Platelet count is independently associated with insulin resistance in non-obese Japanese Type 2 Diabetes.

[4]. Benhalima K. \&Mathieu C. (2009), 'Challenges in the Management of Hyperglycaemia in Type 2 Diabetes', International Diabetes Federation Diabetes Atlas fourth edition Publication 2009; 2 - 7 .

[5]. Charles, F. A. (1998): Endocrinology, In: Mayo Internal Medicine Board Review, Udaya B.S. P. Millhouse O.E. Learn Ms (eds), $3^{\text {rd }}$ Edition Raven, Lippincott: 187-298.

[6]. Chinenye, S. Ogbera, A. O. (2013). Socio-cultural aspects of diabetes mellitus in Nigeria. J. Soc Health Diabetes 1:15-21.

[7]. Cox DJ, Gonder-Frederick L (1992). Review Major developments in behavioral diabetes research. J Consult Clin Psychol; 60(4):628-38.

[8]. Diabetes Care and Education Committee of the Banting and Best Diabetes Centre, Faculty of Medicine of University of Toronto (2009) 'Approach to the Management of Diabetes Mellitus $7^{\text {th }}$ Edition', Diabetes Care and Education Committee of the Banting and Best Diabetes Centre, Faculty of Medicine of University of Toronto 2009, www.bbdc.org/diabetesmanagement.

[9]. DiMatteo MR (2004). Social support and patient adherence to medical treatment: a meta-analysis. Health Psychol; 23(2):207-18. 
[10]. Fabiyi, A. K. Kolawole B. A., Adeshinto, O. Ikem, R. T. (2002): The impact of knowledge, attitude, practice and belief of type two Nigerian diabetes patients on drug compliance. Diabetes, Int. 291:15-17.

[11]. Fisher L, Chesla CA, Skaff MM, et al (2000). The family and disease management in His- panic and European-American patients with type 2 diabetes. Diabetes Care; 23:267 -272 Fowler M. J. (2010), 'Diagnosis, Classification, and Lifestyle Treatment of Diabetes', Clinical Diabetes 2010; 28: $79-86$

[12]. Macaulay A. C., M.D., Paradis G., Potvin L., Ph.D., Cross E. J., Saad-Haddad C., McComber A., Desrosiers S., Kirby R., Montour L. T. Lamping D. L., Leduc N., \& Rivard M. (1997), 'The Kahnawake Schools Diabetes Prevention Project: Intervention, Evaluation, and Baseline Results of a Diabetes Primary Prevention Program with a Native Community in Canada', Preventive Medicine 1997; 26: 779-790.

[13]. Osborn CY, Egede LE (2010). Validation of an information-motivation-behavioral skills model of diabetes self-care (IMB-DSC). Patient Educ Couns ; 79:49-54

[14]. Pereira MG, Berg-Cross L, Almeida P, Machado JC (2008). Impact of family environment and support on adherence, metabolic control, and quality of life in adolescents with diabetes. Int J Behav Med; 15(3):187-93.

[15]. Rosland AM, Kieffer E, Israel B, Cofield M, Palmisano G, Sinco B, Spencer M, Heisler M (2008). When is social support important? The association of family support and professional support with specific diabetes self-management behaviors. J Gen Intern Med; 23(12):1992-9.

[16]. Scottish Intercollegiate Guidelines Network (2010), 'Management of diabetes. A national clinical guideline'. Scottish Intercollegiate Guidelines Network 2010; pg $5-8$.

[17]. Tang TS (2008). Brown MB, Funnell MM, Anderson RM. Social support, quality of life, andself carebehaviorsamongAfrican Americans with type 2 diabetes. Diabetes Educ;34:266 -276

[18]. Wokoma, F. S. (2002): Diabetes and Hypertension in Africa. An Overview Diabetes Int. 12 (12):36-40 